\title{
Numerical Investigation into the Distributor Design in Radial Flow Adsorber
}

\author{
Yongliang Chen ${ }^{1}$, Yao $\mathrm{Li}^{2}$, Haiqing $\mathrm{Si}^{2}{ }^{2}$, Bing Wang ${ }^{2}$, Haibo Wang ${ }^{2}$, \\ Yingying Shen ${ }^{2}$ and Ziqiang Qin ${ }^{2}$ \\ ${ }^{1}$ College of Aerospace Engineering, Nanjing University of Aeronautics and \\ Astronautics, Nanjing 211106, Jiangsu, China \\ 2 College of Civil Aviation and Flight, Nanjing University of Aeronautics and \\ Astronautics, Nanjing 211106, Jiangsu, China
}

Received 2 January 2019; Accepted (in revised version) 16 March 2019

\begin{abstract}
Air flow distribution in radial flow adsorber was numerically investigated using computational fluid dynamics (CFD) method, which was proved to be applicable to study the problem of non-uniform distribution in radial flow adsorber. Results showed that the degree of non-uniformity was more serious in desorption process than that is adsorption process. Therefore, it was considered that the non-uniform distribution of flow in a radial flow adsorber was mainly manifested in the desorption process. Optimum design of distributor parameters can improve the flow distribution in adsorber. Meanwhile, three different structures of distributor and the effect of breathing valve were analyzed. Results revealed that truncated cone is more effective than tubular and conical distributors in flow distribution. By inserting the truncated cone in central channel, desorption uniformity was increased by $6.56 \%$ and the breakthrough time of $\mathrm{CO}_{2}$ was extended from $564 \mathrm{~s}$ to $1138 \mathrm{~s}$ in the adsorption process. The "dead zone" problem at the top of adsorber during the desorption process was solved by opening breathing valve, which prolonged the working life of adsorber and was proved to have less effect on the uniform of airflow.
\end{abstract}

AMS subject classifications: $76 \mathrm{~S} 05$

Key words: CFD method, air separation, radial flow adsorber, adsorption, desorption.

\section{Introduction}

Industrial gas, oxygen and nitrogen are primarily obtained by air separation now [1, 2]. However, in addition to industrial gases, such as nitrogen, oxygen that required for production, it also contains some impurities, like carbon dioxide and water vapor.

*Corresponding author.

Email: sihaiqing@126.com (H. Q.Si) 


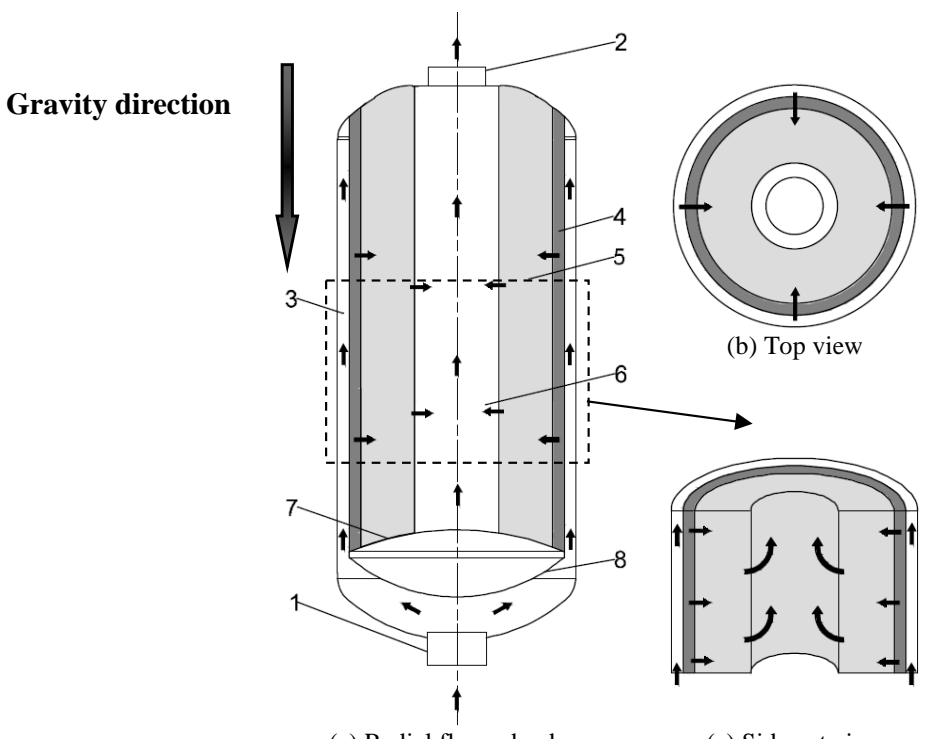

(a) Radial flow adsorber

(c) Side cut view

Figure 1: Schematic of the vertical radial flow adsorber and radial flow pattern in adsorption process 1-inlet; 2-outlet; 3-annular channel; 4-alumina layer; 5-molecular sieve layer; 6-central channel; 7-spherical dish head; 8-deflector.

Once these impurities enter the adsorbers, it will precipitate in low temperature heat exchanger, turbines and rectification tower [3]. Therefore, the separation process of air must be pre-purified [4]. As one of the purifiers, vertical radial flow adsorber has many advantages such as small footprint, low bed pressure drop and low regenerative energy consumption [5]. Compared with the traditional vertical axial flow adsorber and horizontal radial flow adsorber, vertical radial flow adsorber is more suitable for the development of large air separation equipment [6,7].

As shown in Fig. 1, vertical radial flow adsorber mainly consists of four parts: annular channel, activated alumina layer, molecular sieve layer and central channel. In adsorption process, processed air enters the annular channel from the inlet by air compressor, and then it passes through the perforated plate into the alumina layer. After the removal of water vapor, dry air reaches the molecular sieve layer to adsorb carbon dioxide, acetylene and other hydrocarbons. Finally, the processed air is collected in the central channel and discharged from the outlet [8]. Desorption process is just reverse, waste nitrogen enters central channel at the top of the adsorber, travels through molecular sieve horizontally and activated alumina, and exits at the bottom of adsorber. In these processes, due to the unique structure of the radial flow adsorber, non-uniform flow distribution usually exists in a vertical radial flow adsorber, which significantly decreases the utilization of adsorbents, reduces the breakthrough time and even causes safety accidents [6].

Considering the similarity of the flow in an adsorber, cylindrical annulus and reactor, we draw on the experience of related research on many cylindrical annulus and RFBR 
(radial flow bed reactor). Mebarek-Oudina et al. [9-11] conducted a numerical simulation to study natural convection and heat transfer in cylindrical configuration filled. The credibility of the numerical simulation method in the study of fluid flow in cylinder and annulus was verified. Kareeri et al. [12] considered that the main factor affecting the uniformity was cross-sectional area of the central pipe and the annular channel. Genkin et al. [13] derived mathematical models of the flow in the radial flow reactor from the energy conservation equation, and found that the gas distribution profile was a function of the central pipe porosity and the ratio of cross-sectional area of the central pipe to that of the annular channel. Tang et al. [14] studied the effect of the conical distributor on the flow field in the central channel based on the CFD software. The simulation results showed that the conical distributor has a significant positive effect on the uniformity of the airflow during the adsorption process and the desorption process. Rui et al. [15] proposed a new parallel connection device, and established a numerical model of the vertical radial flow adsorber with parallel connection device. The calculation results show that this design can effectively solve the problem of uneven flow field. Tian et al. [16] proposed a novel radial adsorber by parallel layered beds. By the numerical simulation analysis, the results showed that this design could better meet the requirements of large-scale air separation in terms of achieving good pre-purification performance under the premise of low energy consumption. Li et al. [17] adopted numerical simulation methods based on the ANSYS Fluent 15.0 software to study flow pattern in radial flow adsorber, the results showed that the optimization of the ratio of cross-sectional area of the central pipe to that of the annular channel, and the design of the distributor can improve the air uniformity significantly.

The above studies provide a reference for the design of adsorber, which shows the reliability and rationality of the numerical simulation of the flow field in a radial flow adsorber. However, most numerical simulations are based on a simplified model that eliminates the spherical dish head and deflector [5, 6, 12, 14, 15, 18-22]. In fact, due to the diversion of the deflector, the radial velocity of the process air entering the annular channel is large and can not be completely ignored. Secondly, the research on the specific structure of the distributor in the central channel is still insufficient. With the development of large-scale air separation, adsorbents demand a larger volume ratio, which results in a slender annular channel. However, with too large height-diameter ratio of annular channel, traditional conical distributor can not meet the requirement of uniform air flow. Finally, the vast majority of studies about design of adsorber are based on the adsorption process. In fact, the desorption process, higher requirements for uniformity, directly determines gas purity and economic benefits.

The numerical simulation based on the Computational Fluid Dynamics (CFD) Software ANSYS Fluent 15.0 is adopted to study the problem of non-uniformity distribution in radial flow adsorber, and the design of truncated cone in central channel is presented in the paper. This design not only improves the uniformity of air distribution in desorption process, but also maximizes the utilization of adsorbents in adsorption process. Finally, the problem of "dead zone" at the top of the adsorber is solved by setting the 
breathing valve at the top of adsorber.

\section{CFD simulation of adsorption and desorption process}

\subsection{Geometrical model}

Since adsorber structure is complex, this paper only considers the main structure that affects air flow distribution, just as shown in Fig. 2, which is provided by Suzhou Xinglu Air Separation Plant Technology and Development Co., Ltd. The relevant sizes are shown in Tables 1-2. A two-dimensional (2D) axisymmetric finite element model has proven to be applicable by Tang [14], Tian [16] and Li [17]. Comparing with 3D model, 2D axisymmetric model can reduce computational complexity and shorten the computing period.

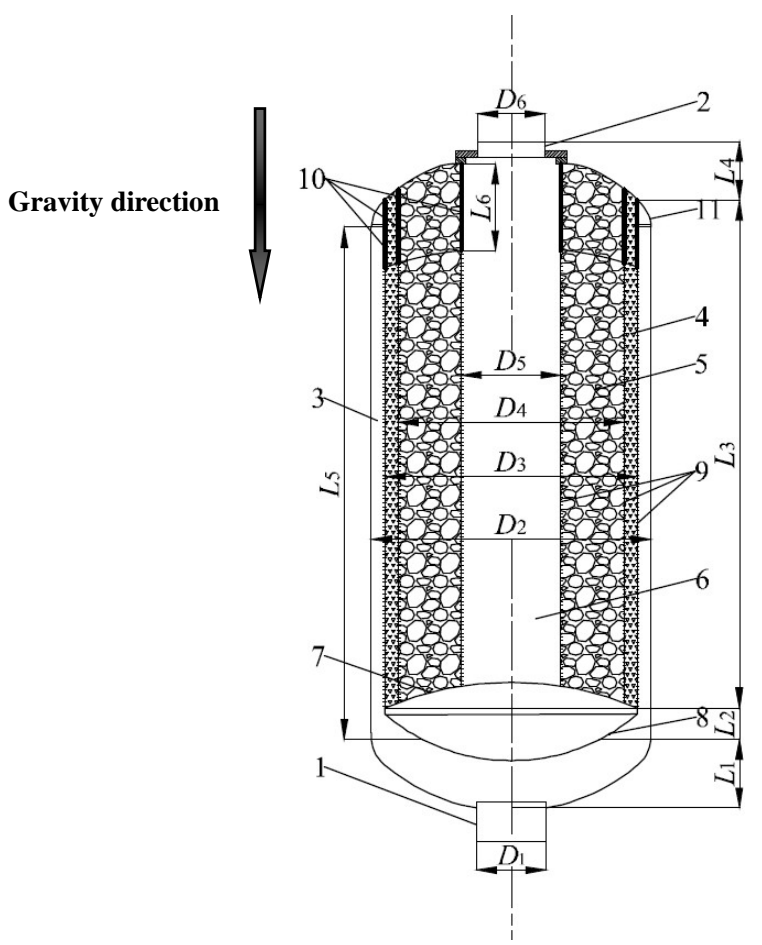

Figure 2: Schematic diagram of axisymmetric physical model of vertical radial flow adsorber 1-inlet; 2-outlet; 3annular channel; 4-alumina layer; 5-molecular sieve layer; 6-central channel; 7-spherical dish head; 8-deflector; 9-perforated plates; 10-imperforated plates; 11-channel steel.

Table 1: Related diameters of the adsorber $(\mathrm{mm})$.

\begin{tabular}{||cccccc||}
\hline$D_{1}$ & $D_{2}$ & $D_{3}$ & $D_{4}$ & $D_{5}$ & $D_{6}$ \\
\hline 200 & 840 & 759 & 679 & 270 & 200 \\
\hline
\end{tabular}


Table 2: Related lengths of the adsorber $(\mathrm{mm})$.

\begin{tabular}{||cccccc||}
\hline$L_{1}$ & $L_{2}$ & $L_{3}$ & $L_{4}$ & $L_{5}$ & $L_{6}$ \\
\hline 216.4 & 76 & 1534 & 176 & 1514 & 261.2 \\
\hline
\end{tabular}

\subsection{Mathematical models}

\subsubsection{Assumptions}

In order to simplify the mathematical model to describe the dynamic adsorption of air in adsorber and the dynamic process of mass transfer and heat transfer in adsorbent, the following assumptions need to be taken [22,23]:

(1) The air contains only water vapor and carbon dioxide, adsorption of other gases in the air is ignored, such as nitrogen and a small amount of hydrocarbons.

(2) Water vapor and carbon dioxide are considered as incompressible ideal gases when they are dispersed in the adsorbents.

(3) Adsorption heat is constant and does not vary with temperature.

(4) Particle radius of the activated alumina and the 13X molecular sieve are same, the density and porosity of activated alumina and 13X molecular sieve are fixed.

(5) The fluid flows along the radial direction in adsorbent bed.

(6) The thermal conductivity and concentration gradients along the axial and circumference directions is neglected in adsorbent bed.

\subsubsection{The governing equations of the adsorption process}

(1) Linear driving force (LDF) model

Mass transfer resistance of molecular sieves is mainly controlled by the large pore diffusion, and the effect of micropore diffusion can be neglected. Therefore, mass transfer rate can be expressed by LDF model $[24,25]$

$$
\frac{\partial q_{i}}{\partial t}=k\left(q_{i}^{*}-q_{i}\right)
$$

where $k$ is mass transfer coefficient of component; $q_{i}^{*}$ is equilibrium absorption capacity of the component $i$, mol $\cdot \mathrm{kg}^{-1} ; t$ is the time.

Axial dispersion coefficient and mass transfer resistance [26] can be calculated by

$$
\frac{1}{k_{c}}=\frac{\rho_{p} D_{L}}{\varepsilon u^{2}}+\frac{1}{k_{c}^{0}}
$$


where the $D_{L}$ is the axial dispersion coefficient, $\mathrm{m}^{2} \cdot \mathrm{s}^{-1} ; u$ is the gas velocity, $\mathrm{m} \cdot \mathrm{s}^{-1} ; \varepsilon$ is bed porosity; $\rho_{p}$ is the adsorbent bulk density, $\mathrm{kg} \cdot \mathrm{m}^{-3} ; k_{c}$ is the LDF mass transfer coefficient, $\mathrm{s}^{-1} ; k_{c}^{0}$ is the uncorrected LDF mass transfer coefficient, $\mathrm{s}^{-1}$

$$
\frac{1}{k_{c}^{0}}=\frac{R_{p}^{2}}{15 \varepsilon D_{p}}+\frac{R_{p}}{3 k_{f}},
$$

where the $k_{f}$ film mass transfer coefficient, $\mathrm{s}^{-1} ; D_{P}$ is the pore diffusivity, $\mathrm{m}^{2} \cdot \mathrm{s}^{-1} ; R_{P}$ is the particle radius $m$.

The flow in adsorption region is generally at low Reynolds number [26], when $3<$ $\operatorname{Re}<10000$,

$$
\begin{aligned}
k_{f} & =\left(2.0+1.1 S_{c}^{1 / 3} R e^{0.6}\right) \frac{D_{m}}{2 R_{p}}, \\
S_{c} & =\frac{v}{D_{m}}, \\
R e & =\frac{2 R_{p} \varepsilon u}{v} .
\end{aligned}
$$

The pore diffusivity $D_{p}$, Knudsen diffusion coefficient $D_{k}$ and molecular diffusion coefficient $D_{m}$ can be represented as:

$$
\begin{aligned}
& \frac{1}{D_{p}}=\tau_{p}\left(\frac{1}{D_{K}}+\frac{1}{D_{m}}\right), \\
& D_{k}=9700 r_{p} \sqrt{\frac{T}{M^{\prime}}} \\
& D_{m}=\frac{0.0101 T^{1.75} \sqrt{\frac{1}{M_{1}}+\frac{1}{M_{2}}}}{\left.P\left[\left(\sum v_{1}\right)^{1 / 3}+\sum v_{2}\right)^{1 / 3}\right]^{2}} .
\end{aligned}
$$

The axial dispersion coefficient $D_{L}$ and tortuosity factor $\tau_{p}$ are described as:

$$
\begin{aligned}
& \frac{D_{L}}{D_{m}}=0.7+0.5 \frac{\operatorname{Re} S_{c}}{\varepsilon}, \\
& \tau_{p}=1 / \varepsilon .
\end{aligned}
$$

Where $M$ is the molecular weight, $\mathrm{g} \cdot \mathrm{mol}^{-1} ; P$ is the partial pressure, atm; $\sum v$ is the molecular diffusion volume, $\mathrm{m}^{3} \cdot \mathrm{mol}^{-1}$. The molecular diffusion volume is constant $\left(\sum v_{1}=1.31 \times 10^{-5} \mathrm{~m}^{3} \cdot \mathrm{mol}^{-1}, \sum v_{2}=2.69 \times 10^{-5} \mathrm{~m}^{3} \cdot \mathrm{mol}^{-1}\right)$ at atmospheric pressure.

(2) Adsorption isotherm equation

Compared with Langmuir-Freundlich, Tòth, and the D-A models presented by Epiepang [27] et al., D-A model was found to be best fit especially in the low pressure 
range:

$$
\begin{aligned}
& V=V_{0} \cdot \exp \left[-\left(C \ln \frac{P_{s}}{P}\right)^{m}\right], \\
& C=\frac{R T}{\beta F},
\end{aligned}
$$

where $m$ represents the distribution of adsorption energies from the adsorbent, the larger the $m$ value, the narrower the micropores, whereas small $m$ value represents adsorbents with wide ranges of pore size; $V$ is volume adsorbed in micropores, $\mathrm{cm}^{3} \cdot \mathrm{g}^{-1} ; V_{0}$ is a limiting micropore volume, $\mathrm{cm}^{3} \cdot \mathrm{g}^{-1} ; P_{S}$ is the saturation pressure, atm; $R$ is the gas constant, $\mathrm{J} \cdot\left(\mathrm{mol}^{-1} \cdot \mathrm{K}^{-1}\right) ; T$ is the absolute temperature, $K . \beta F$ is the fitting parameter of $\mathrm{D}-\mathrm{A}$ equation.

(3) Mass conservation equation

$$
\begin{aligned}
& \frac{\partial\left(\varepsilon \rho_{f} Y_{i}\right)}{\partial t}+\nabla\left(\varepsilon \rho_{f} \vec{u} Y_{i}\right)-\nabla\left(\varepsilon \rho_{f} D_{i, m} \nabla Y_{i}\right)=-S_{i} \\
& S_{i}=M_{i} \rho_{p}(1-\varepsilon) \frac{\partial q_{i}}{\partial t}
\end{aligned}
$$

where $\rho_{f}$ is gas density, $\mathrm{kg} \cdot \mathrm{m}^{-3} ; Y_{i}$ is mass fraction of the component $i ; D_{i, m}$ is mixed gas diffusion coefficient of the component $i, \mathrm{~m}^{2} \cdot \mathrm{s}^{-1} ; S_{i}$ is mass source term of the component $i, \mathrm{~kg} \cdot\left(\mathrm{m}^{-3} \cdot \mathrm{s}^{-1}\right) ; M_{i}$ is molar mass of the component $i, \mathrm{~kg} \cdot \mathrm{mol}^{-1}$.

(4) Total mass conservation equation

$$
\begin{aligned}
& \frac{\partial\left(\varepsilon \rho_{f}\right)}{\partial t}+\nabla(\varepsilon \rho, \vec{u})=-S_{m}, \\
& S_{n}=\sum_{i=1}^{n} S_{i} .
\end{aligned}
$$

(5) Momentum equation

$$
\frac{\partial\left(\rho_{f} \vec{u}\right)}{\partial t}+\left(\rho_{f} \vec{u} \cdot \nabla \vec{u}\right)=-\nabla p+\nabla(\tau)+\rho_{f} \vec{g}+\vec{S},
$$

where $p$ is the gas pressure, $\mathrm{Pa} ; \mathrm{g}$ is the acceleration of gravity, $\mathrm{m} \cdot \mathrm{s}^{-2}$.

In this paper, adsorption bed and perforated plates are difficult to model directly. Therefore, the adsorption bed is simplified into a porous medium model, and the perforated plates are simplified into the porous jump model. The porous jump model is a one-dimensional simplification of the porous medium model, which ignores permeability.

For the source term of adsorption bed:

$$
\vec{S}=-\left(\mu \frac{\vec{u}}{\alpha}+C_{2} \rho_{f}|\vec{u}| \vec{u}+\sum_{i=1}^{n} S_{i} \vec{u}\right),
$$


where $C_{2}$ is the inertial resistance factor, $\mathrm{m}^{-1} ; \alpha$ is the permeability, $\mathrm{m}^{2}$; The third item is the effect of adsorption process on the momentum equation. $C_{2}, \alpha$ can be calculated by Ergun equation [28]:

$$
\begin{gathered}
\alpha=\frac{d_{p}^{2} \varepsilon^{3}}{150(1-\varepsilon)^{2}}, \\
C_{2}=\frac{3.5(1-\varepsilon)}{d_{p} \varepsilon^{3}},
\end{gathered}
$$

where $d_{p}$ is diameter of the adsorbent particles, $m$.

The source term of perforated plate:

$$
\vec{S}=-\left(\frac{1}{2} C_{2} \rho_{f}|\vec{u}| \vec{u}\right)
$$

where $C_{2}$ can be determined according to the empirical formula:

$$
C_{2}=\frac{1}{C_{1}^{2} d x}\left(\frac{1}{\varphi^{2}}-1\right)
$$

where $d x$ is the plate thickness, $m ; \varphi$ is porosity of the perforated plate; $C_{1}$ is relative to the Reynolds number $(R e)$ and the ratio of plate thickness to hole radius. When $R e>4000$ and $\frac{d_{x}}{r}>1.6$,

$$
C_{1} \approx 0.98
$$

(6) Gas state equation

$$
p_{i}=\frac{\rho_{i} R_{i} T}{M_{i}}=\frac{Y_{i} \rho_{f} R T}{M_{i}}
$$

(7) Energy equation

$$
\begin{aligned}
& \frac{\partial}{\partial t}\left(\varepsilon \rho_{f} E_{f}+(1-\varepsilon) \rho_{s} E_{s}\right)+\nabla\left(\vec{u}\left(\rho_{f} E_{f}+p\right)\right)=\nabla\left(k_{e f f} \nabla T+(\tau \vec{u})\right)+S_{f}, \\
& S_{f}=(1-\varepsilon) \rho_{s} \sum_{i=1}^{n}\left(\Delta H_{i} \frac{\partial q_{i}}{\partial t}\right),
\end{aligned}
$$

where $E_{f}$ is total energy contained in fluid, $\mathrm{J} \cdot \mathrm{kg}^{-1} ; E_{s}$ is total energy contained in solid, $\mathrm{J} \cdot \mathrm{kg}^{-1} ; k_{e f f}$ is the effective heat transfer coefficient of bed layer, $\mathrm{W} \cdot\left(\mathrm{m}^{-2} \cdot \mathrm{K}^{-1}\right) ; \tau$ is stress tensor, $\mathrm{kg} \cdot\left(\mathrm{m}^{-1} \cdot \mathrm{s}^{-2}\right) ; \Delta H_{i}$ is adsorption heat of gas, $\mathrm{J} \cdot \mathrm{mol}^{-1}$. 
Table 3: Fitting results of DA equation parameters at $293 \mathrm{~K}$.

\begin{tabular}{||ccccc||}
\hline & $P_{s} / \mathrm{atm}$ & $V_{0} / \mathrm{m}^{3} \cdot \mathrm{kg}^{-1}$ & $\mathrm{C}$ & $m$ \\
\hline $\mathrm{H}_{2} \mathrm{O} / 13 \mathrm{X}$ & 1.00 & $3.005 \mathrm{E}-4$ & 0.125 & 6.0 \\
$\mathrm{CO}_{2} / 13 \mathrm{X}$ & 57.53 & $3.004 \mathrm{E}-4$ & 0.120 & 3.0 \\
$\mathrm{H}_{2} \mathrm{O} / \gamma-\mathrm{Al}_{2} \mathrm{O}_{3}$ & 1.00 & $5.277 \mathrm{E}-5$ & 0.107 & 6.0 \\
$\mathrm{CO}_{2} / \gamma-\mathrm{Al}_{2} \mathrm{O}_{3}$ & 57.53 & $3.153 \mathrm{E}-5$ & 0.147 & 2.5 \\
\hline
\end{tabular}

Table 4: Porous and porous jump model parameters.

\begin{tabular}{||ccc||}
\hline & Parameters & Units \\
\hline Bed porosity $\varepsilon$ & 0.28 & \\
Particle diameter $d_{p}$ & 4 & $\mathrm{~mm}$ \\
Porosity of perforated plates $\varphi$ & 0.39 & \\
Thickness of perforated plates $d x$ & 4 & $\mathrm{~mm}$ \\
\hline
\end{tabular}

\subsubsection{Determination of related parameters}

At $293 \mathrm{~K}$, three parameters of DA equation are determined by Epiepang's experiments [27], as shown in Table 3.

Values of porous medium and porous jump model are shown in Table 4 . The permeability and inertial resistance factor are calculated from Eqs. (2.12a), (2.12b) and (2.14).

\subsection{Numerical method and boundary conditions}

The initial conditions and boundary conditions should be determined before the simulation. In the adsorption process, heat and mass transfer process are solved with the cell-based finite volume method (FVM). Coupled algorithm is presented to solve the coupled equations of the pressure and the velocity, the second upwind scheme and doubleprecision implicit solver are used to solve equations of energy, momentum and component. PRESTO! Scheme is employed in pressure discretization because of the porous medium model. In this process, a constant change in the concentration of $\mathrm{H}_{2} \mathrm{O}$ and $\mathrm{CO}_{2}$ caused by adsorption was monitored at the outlet to determine the breakthrough time of the adsorber, which is an important engineering parameter. The concentration variations of components in the adsorption process with time is importance in this research, so the adsorption process modelled as unsteady. In order to simulate the adsorption process of two-component gas $\left(\mathrm{CO}_{2}, \mathrm{H}_{2} \mathrm{O}\right)$ on the alumina layer and the molecular sieve layer, the mass transfer equation, adsorption isotherm equation, mass source terms and energy source terms are compiled in ANSYS Fluent 15.0 by UDF (User-Defined Functions). The two-component D-A equation is applied to define the adsorption equilibrium, LDF model is used to describe the mass transfer process, so the component mass source and the energy source can be defined directly using the macro of DEFINE_SOURCE.

The content of saturated water vapor and carbon dioxide in the air is very low, the 
Table 5: Boundary condition of adsorption and desorption processes.

\begin{tabular}{||ccccccc||}
\hline Process & Rate of flow $/ \mathrm{m}^{3} \cdot \mathrm{h}^{-1}$ & Pressure $/ \mathrm{Pa}$ & Temperature $/ \mathrm{K}$ & Working medium & Bulk density $/ \mathrm{kg} \cdot \mathrm{m}^{-3}$ & Gravity $/ \mathrm{N} \cdot \mathrm{kg}^{-1}$ \\
\hline Adsorption & 2000 & 101325 & 293 & Air & $\begin{array}{c}\gamma-\mathrm{Al}_{2} \mathrm{O}_{3} 700 \\
13 \mathrm{X} \text { zeolite } 620\end{array}$ & $-9.81(x)$ \\
\hline Desorption & 2000 & 101325 & - & Waste Nitrogen & $\begin{array}{c}\gamma-\mathrm{Al}_{2} \mathrm{O}_{3} 700 \\
13 \mathrm{X} \text { zeolite } 620\end{array}$ & $-9.81(x)$ \\
\hline
\end{tabular}

mass fraction is about $0.46 \%$ and $0.06 \%$ respectively under the typical operating conditions $\left(P=0.6 \mathrm{MPa}, T=15^{\circ} \mathrm{C}\right)$ of the adsorber, so the influence of the desorption process of water vapor and carbon dioxide on the flow pattern can be neglected. Therefore, in the desorption process, only the flow pattern in the adsorber was considered which means that the change of the gas flow is independent of time, so a steady method was adopted in this process. The coupling equations of pressure and velocities were solved with the SIMPLE algorithm.

The boundary conditions for the adsorption and desorption processes are shown in Table 5. The airflow in the adsorber is a turbulent flow and is simulated by standard $k-\varepsilon$ model. In the unsteady case, $d t$ is the ratio of typical cell size to the characteristic flow velocity, was set to 0.01 . In adsorption process, the inlet condition of the feed air can be regarded as the boundary condition. In desorption process, the adsorbent is usually purged by waste nitrogen, so the inlet condition of the waste nitrogen can be regarded as the boundary condition.

\subsection{Meshing and mesh sensitivity analysis}

\subsubsection{Meshing}

The quality of mesh affects the accuracy of numerical calculation. However, due to computer hardware constraints, the number of grid should not be too large. As the model is relatively regular, a professional mesh generation software ICEM-CFD 15.0 is used to generate quadrilateral grid. The grid of radial flow adsorber is shown in Fig. 3, the mesh of the near walls, perforated plates and adsorption area is refined.

\subsubsection{Mesh sensitivity analysis}

In the initial stage, 7,500 grids are adopted, then the number of grids is increased by 2 times. Fig. 4 shows static pressure in annular channel changes over axial height at various

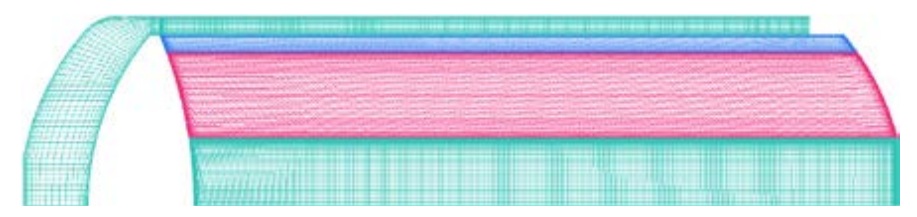

Figure 3: Schematic diagram of axisymmetric mesh of vertical radial flow adsorber. 


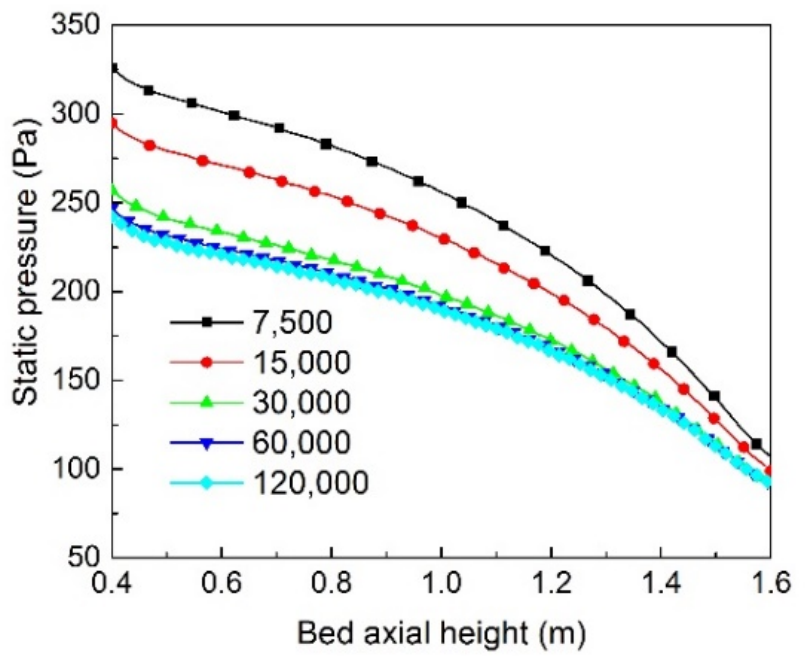

Figure 4: Static pressure in annular channel changes over axial height at various grid numbers.

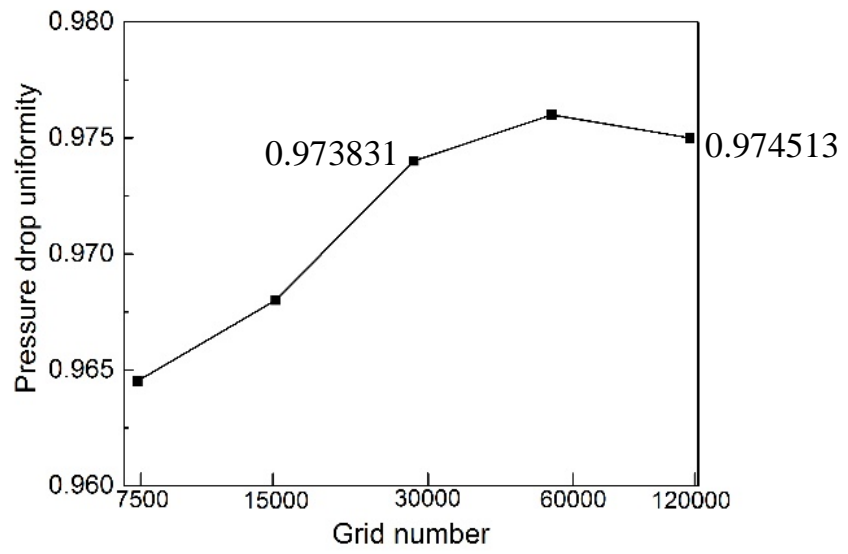

Figure 5: Pressure drop uniformity changes along with the increase of the grid number.

grid numbers, the three curves with the number of grids $30,000,60,000$, and 120,000 are closed and even overlapped. Fig. 5 displays the pressure drop uniformity changes along with the increase of the grid number. As can be seen from the figure, the pressure drop uniformity increases significantly and approaches to a flat after the grid number reaches 30,000 , and the error is only around $0.07 \%$ when the range of grid number is from 30,000 to 120,000 . The accuracy of the grid is not improved obviously, which indicates that the grid has reached a high enough precision and the grid number with 30,000 is enough for the present simulation. 


\section{Numerical simulations and analysis}

\subsection{Model validation}

At present, there are few experimental studies on the adsorption and desorption process of radial flow adsorber. So, the experimental study on the RFBR (radial flow bed reactor) is used to verify the correctness of the CFD method used in this paper. In order to ensure the reliability of simulation, the flow patterns of vertical radial flow adsorber and the adsorption process of the air in adsorbent are verified respectively.

\subsubsection{Validation of flow patterns in adsorption process}

Chen [19] et al. conducted an experimental study on the flow characteristics of a radial flow adsorber without considering the effect of the adsorption process on flow field. The height $h$ and diameter of the adsorber are $0.5 \mathrm{~m}$ and $0.18 \mathrm{~m}$, respectively, the diameter of inlet and the central channel is $0.05 \mathrm{~m}$, and the thickness of the adsorbent bed is $0.09 \mathrm{~m}$. The inlet velocity $v_{0}=7.94 \mathrm{~m} \cdot \mathrm{s}^{-1}$ and the perforated plates porosities of annular channel and central channel are 0.2813 and 0.2844 , respectively. Adsorption bed is filled with porcelain ball by a diameter of $0.006 \mathrm{~m}$ and a porosity of 0.539 to simulate the flow resistance of the adsorbent.

The dimensionless axial velocity $V_{d}=\frac{v_{1}}{v_{0}}$, and the dimensionless height of annular flow channel $H=\frac{y}{h}\left(y, v_{1}\right.$ are the axial height and axial velocity of the measuring point, respectively). The axial velocity of air at the dimensionless height of $0.1,0.2,0.3,0.4,0.5,0.6$, 0.7 , and 0.8 is measured by the Particle Image Velocimetry (PIV), and its average value are calculated by normalization method, as are shown by " $\mathbf{\square}$ " in Fig. 6 . The numerical results are displayed by the symbol " $\triangle$ " in Fig. 6 using the present method in the paper. By comparing these data, it is clearly seen that the calculated results and the test ones have the same trend, it indicates that the model established in the paper is correct and reliable.

\subsubsection{Validation of flow patterns in desorption process}

In desorption process, the air flow pattern in adsorber belongs to "OW-Z" [29], which means the flow direction through the bed can be outward (centrifugal, designated by "OW") and flows in the central channel and annular channel can be in the same $(Z)$. Heggs et al. [21] conducted an experimental study and numerical predictions on the "OW-Z" flow in an RFBR. The bed length $h$ is $0.26 \mathrm{~m}$, the diameters of central channel and reactor are $0.126 \mathrm{~m}$ and $0.34 \mathrm{~m}$, respectively. The packed bed is a multi-layered region, in which the particulate filter is near the central channel and the carbon bed is near the annular channel. The outer diameters of particulate filter and carbon bed is $0.203 \mathrm{~m}$ and $0.330 \mathrm{~m}$, respectively. The inlet velocity $v_{0}=5.68 \mathrm{~m} \cdot \mathrm{s}^{-1}$ and the perforated plates porosities of annular channel and central channel are 0.326 and 0.1475 , respectively. The voidage of particulate filter is 0.1 and the porosity of carbon bed is 0.412 . 


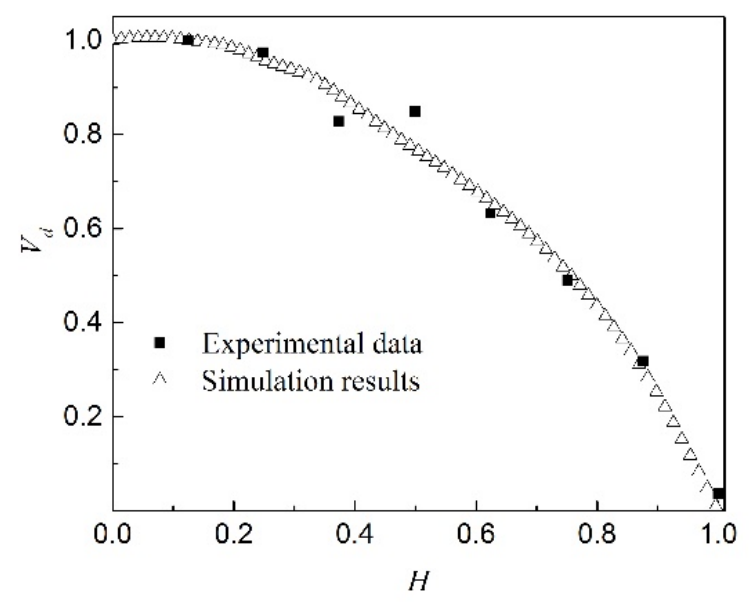

Figure 6: Changes of the dimensionless axial velocity $V_{d}$ along with the dimensionless height $H$ in annular channel.

The pressure profile of the central channel and annular channel was normalized by dividing it by the maximum pressure difference. Figs. 7 and 8 show a comparison of the present CFD study normalized pressure profiles of the center channel and the annular channel, respectively, with those of Heggs et al. [21]. They show that numerical simulating results of present CFD method are in good agreement with the experimental data. Furthermore, the CFD results are closer to the experimental results than the numerical predictions of Heggs et al. [21].

\subsubsection{Validation of adsorption process}

In the experiment of $\mathrm{Li}$ [30-32] et al. the influences of water vapor on the adsorption of carbon dioxide in the high humidity flue-gas streams were studied, and the breakthrough curve of carbon dioxide in molecular sieves was given by the symbol " $\square$ ", as shown in Fig. 9. The adsorber is a cylindrical metal tank with a height of $0.56 \mathrm{~m}$ and a diameter of $0.049 \mathrm{~m}$. The metal tank is filled with spherical particles of molecular sieves with a diameter of $0.002 \mathrm{~m}$, a density of $640.7 \mathrm{~kg} \cdot \mathrm{m}^{-3}$ and a porosity of 0.4 . The volume fraction of carbon dioxide, water vapor and air is $10.5 \%, 3.4 \%$ and $86.1 \%$, respectively. In this experiment, the pressure for the inlet gas stream is $118 \mathrm{kPa}$ and the flow-rate is $70 \mathrm{~L} \cdot \mathrm{min}^{-1}$. The temperature for the feed gas and tank is all controlled at 303K. In order to verify the reliability of the simulation method, numerical analysis of the metal tank is carried out, the results of which are compared with the ones of the test. It can be seen from the comparison that the carbon dioxide breakthrough time in the simulation is $42 \mathrm{~s}$, which is consistent with one of the experiment. At the same time, the breakthrough curves variation tendencies between experiment and simulation are approximate and unanimous, which indicates that the adsorption model in this paper has a high accuracy in predicting adsorption process. 


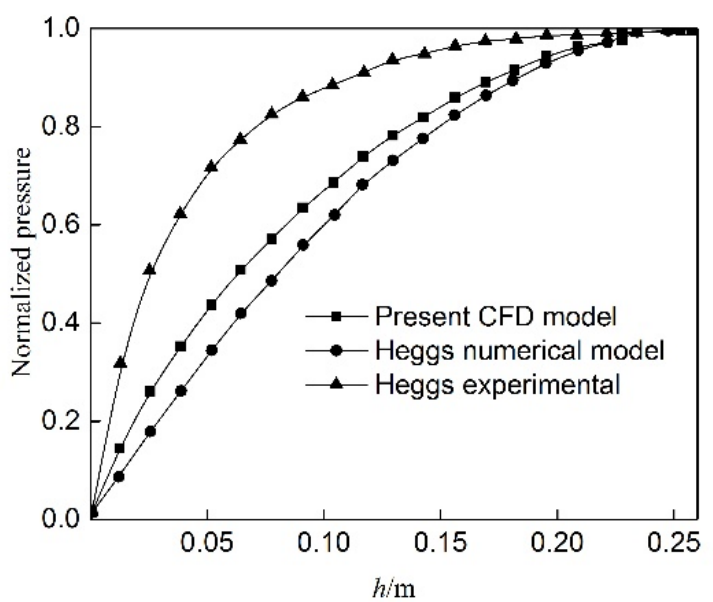

Figure 7: Profile of normalized pressure in the central channel.

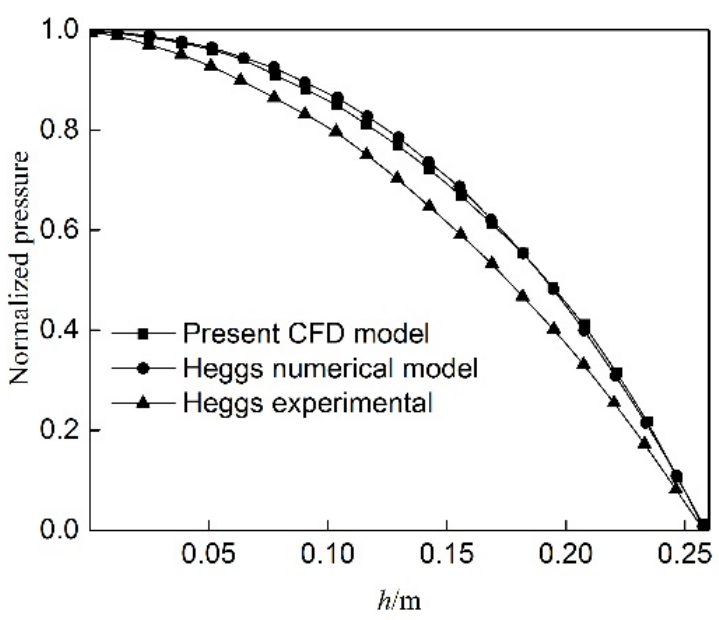

Figure 8: Profile of normalized pressure in the central channel.

\subsection{Radial pressure drop distribution in adsorption and desorption process}

The static pressure in the adsorber is affected by the frictional resistance and the momentum exchange. In adsorption process, the increasing of momentum exchange and frictional resistance can make the static pressure in annular channel rise and fall, respectively. Hence, changes of static pressure depend on the relative value of frictional resistance and momentum exchange. As the diameter of annular channel in this paper is small, the effect of frictional resistance on static pressure is greater than that of momentum exchange, which induced the static pressure presents downward trend in whole. However, both 


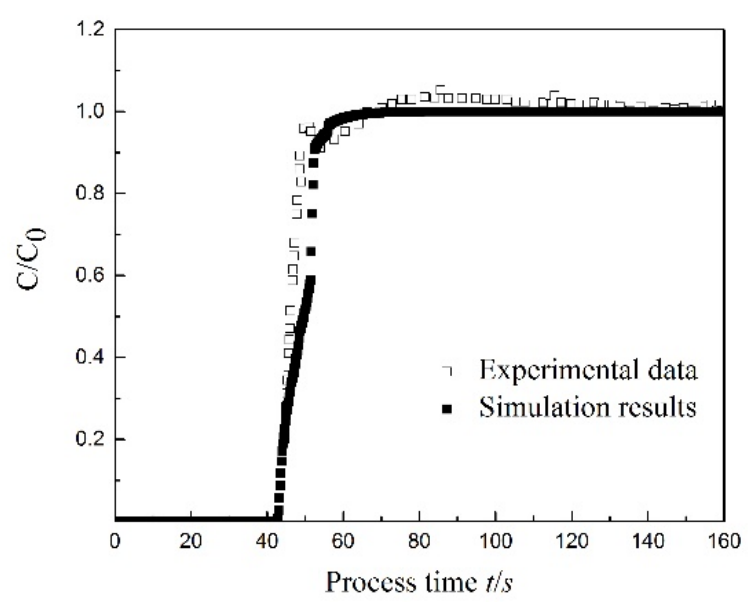

Figure 9: Comparison of numerical results with experimental data for $\mathrm{CO}_{2}$ breakthrough curve.

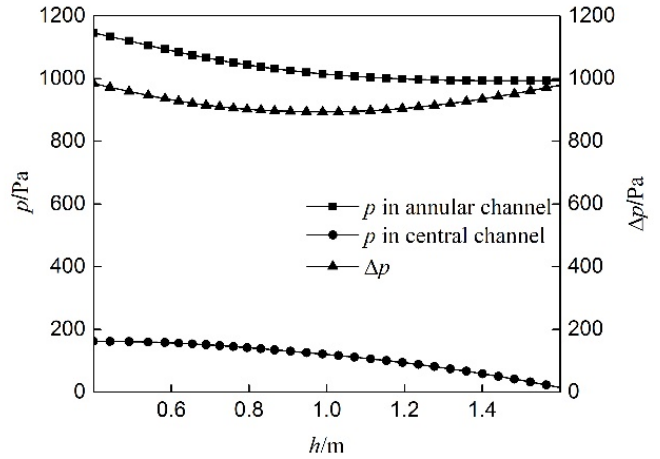

(a)

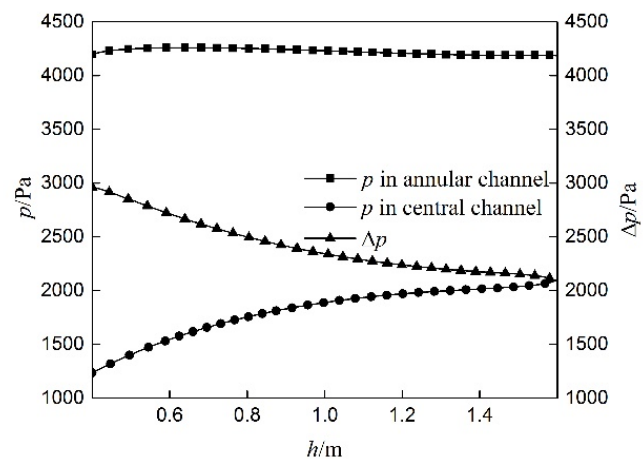

(b)

Figure 10: Pressure changes in radial flow adsorber along with axial height during adsorption and desorption process. (a) The static pressure curves of central and annular channel and pressure drop curve during adsorption process; (b) The static pressure curves of central and annular channel and pressure drop curve during desorption process.

the increasing of momentum exchange and frictional resistance can cause the static pressure to fall in central channel; therefore the static pressure has a clear downward trend. Radial pressure drop across the bed can be expressed as the difference between the static pressure of annular channel and that of central channel, as shown in Fig. 10(a).

On the contrary, as the diameter of central channel is large, the effect of momentum exchange on static pressure is greater than that of frictional resistance in the desorption process, which induced the static pressure presents upward trend in central channel. Furthermore, the static pressure in annular channel decrease gradually, the radial pressure drop across bed presents a clear downward trend under the combined action of static 
pressure in central and annular channel, as shown in Fig. 10(b).

In order to quantitatively analyse the air flow distribution in radial flow adsorber, it is considered that the pressure drop across the bed can be replaced by the pressure difference between the annular channel and central channel at the same height. Therefore, the formula of pressure drop uniformity is introduced to indicate the air flow uniformity in the adsorber [24]

$$
\begin{aligned}
& \eta=1-\sqrt{\frac{1}{n-1} \sum_{i=1}^{n}\left(\Delta p_{i} / \Delta \bar{p}-1\right)^{2}}, \\
& \Delta \bar{p}=\frac{\sum_{i=1}^{n} \Delta p_{i}}{n},
\end{aligned}
$$

where $\eta$ is the uniformity coefficient; $n$ is the number of data; $\Delta p_{i}$ is static pressure difference at $i, \mathrm{~Pa} ; \Delta \bar{p}$ is the average of the static pressure difference, $\mathrm{Pa}$.

Through the calculations of pressure drop uniformity, the uniformity of adsorption and desorption process is $97.13 \%$ and $90.07 \%$, respectively, which indicates the air flow in desorption process is more uneven compared to that in adsorption process.

\subsection{Comparison of distributors in central channel}

Since the purity of products and the service life of adsorber are directly determined by desorption uniformity, its performance is prioritized. Combined with the research status, this paper presents three kinds of designs of the distributor in central channel: tube with equal-diameter, cone and truncate cone. The best capability design will be obtained by comparing the performance of three distributors in the air flow distribution.

\subsubsection{Numerical simulation of tube}

According to the change of pressure drop during the desorption in Fig. 10(b), the tube is inserted at the bottom of central channel to reduce its diameter. Relying on the analysis above, decreasing the diameter of central channel will make the diameter of the frictional resistance increase, thereby achieving the purpose of the uniform pressure drop. Fig. 11 shows the changes of normalized pressure drop along with the different tubes at the bottom of central channel. It can be seen that after inserting the tube, the radial pressure drop at the corresponding position of the bed reduces for the cross-sectional area of the central channel decreases. Furthermore, the pressure drop decreases as the length $l_{t}$ and diameter $d_{t}$ of tube increases. Table 6 shows the relationships among pressure drop uniformity, $l_{t}$ and $d_{t}$. When $l_{t}=670 \mathrm{~mm}, d_{t}=100 \mathrm{~mm}$, the uniformity of pressure drop can reach the maximum of $95.332 \%$.

\subsubsection{Cone}

So as to achieve a uniform pressure drop, the conical distributor has a decreasing crosssectional area to accommodate the distribution of the pressure drop. Fig. 12 shows the 
Table 6: Changes of pressure drop uniformity along with the height and diameter of tube during the desorption process.

\begin{tabular}{||ccc||}
\hline Tube length $l_{t} / \mathrm{mm}$ & Tube diameter $d_{t} / \mathrm{mm}$ & Pressure drop uniformity $/ \%$ \\
\hline 660 & 100 & 95.3081 \\
670 & 100 & 95.3326 \\
680 & 100 & 95.3313 \\
670 & 90 & 93.8294 \\
670 & 110 & 94.2530 \\
\hline
\end{tabular}

Table 7: Changes of pressure drop uniformity along with the height and diameter of cone.

\begin{tabular}{||ccc||}
\hline Cone length $l_{t} / \mathrm{mm}$ & Cone diameter $d_{t} / \mathrm{mm}$ & Pressure drop uniformity $/ \%$ \\
\hline 760 & 100 & 89.7685 \\
1000 & 100 & 89.8919 \\
1300 & 100 & 90.3577 \\
1570 & 100 & 90.6729 \\
1570 & 120 & 92.7638 \\
\hline
\end{tabular}

changes of normalized pressure drop along with the different cones at the bottom of central channel. It can be seen that increasing the length $l_{c}$ and diameter $d_{c}$ of the cone can reduce the corresponding radial pressure drop and move the pressure drop to a more optimal direction. Nevertheless, due to the fact that the difference between maximum and minimum pressure drop of the adsorber is nearly 1000Pa, the traditional cone can not meet the requirement of uniformity. Table 7 shows the relationships among the pressure drop uniformity, $l_{c}$ and $d_{c}$. It indicates that pressure drop uniformity becomes better as $l_{c}$ and $d_{c}$ increase, but too slowly. Even if $l_{c}$ and $d_{c}$ increase to the maximum allowed value, the pressure drop uniformity only reached $92.7638 \%$ theoretically.

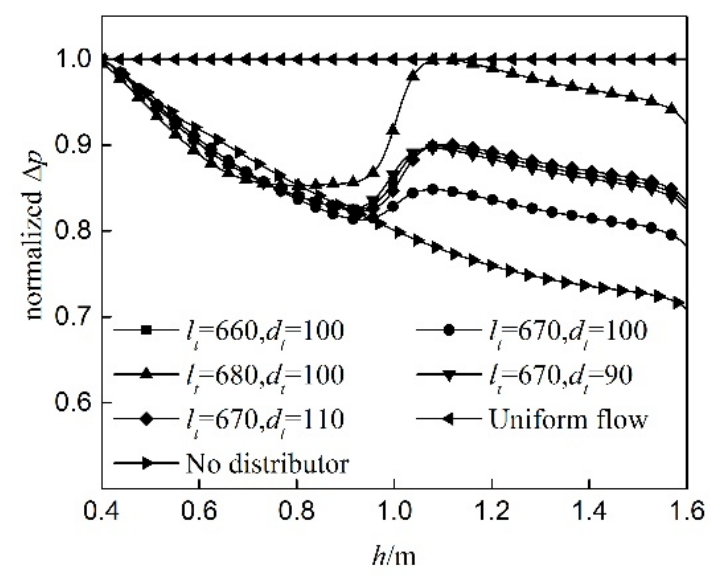

Figure 11: Changes of normalized pressure drop along with the height and diameter of tube during the desorption process. 


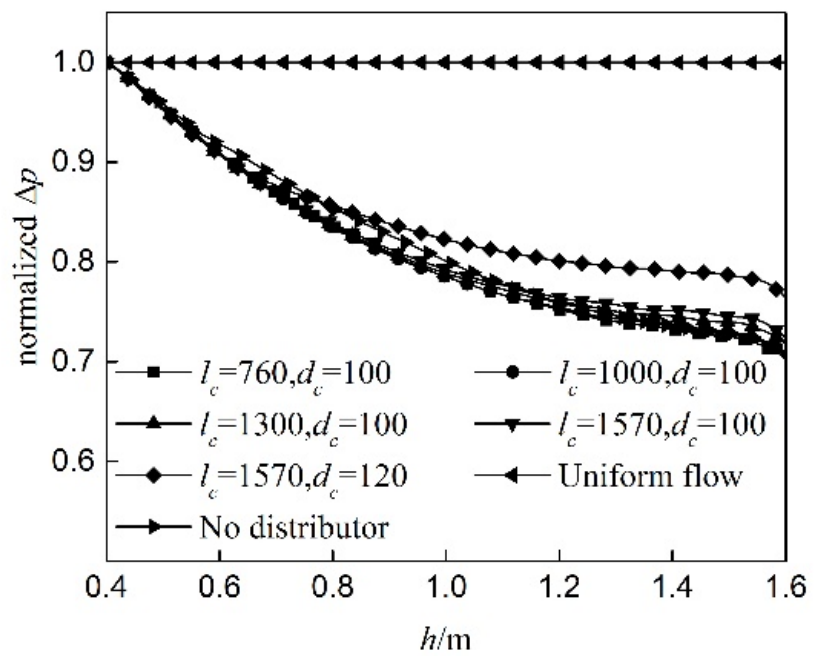

Figure 12: Normalized pressure drop along with the height and diameter of cone during desorption process.

Table 8: Changes of pressure drop uniformity along with the height and diameter of truncated cone.

\begin{tabular}{||cccc||}
\hline $\begin{array}{c}\text { Truncated cone length } \\
l_{f} / \mathrm{mm}\end{array}$ & $\begin{array}{c}\text { Bottom diameter of truncated cone } \\
d_{f b} / \mathrm{mm}\end{array}$ & $\begin{array}{c}\text { Top diameter of truncated cone } \\
d_{f t} / \mathrm{mm}\end{array}$ & $\begin{array}{c}\text { Pressure drop uniformity } \\
/ \%\end{array}$ \\
\hline 650 & 120 & 100 & 96.6181 \\
650 & 130 & 100 & 96.2484 \\
650 & 110 & 100 & 95.9495 \\
650 & 120 & 110 & 93.5444 \\
650 & 120 & 90 & 95.7866 \\
660 & 120 & 100 & 96.6274 \\
660 & 130 & 100 & 96.5446 \\
660 & 110 & 100 & 95.9376 \\
660 & 120 & 110 & 93.6127 \\
660 & 120 & 90 & 95.9434 \\
670 & 120 & 100 & 96.4769 \\
670 & 130 & 100 & 95.7041 \\
670 & 110 & 100 & 95.9765 \\
670 & 120 & 110 & 92.9727 \\
\end{tabular}

\subsubsection{Truncate cone}

A new truncate cone is presented in the paper. The structural parameters of the truncate cone include height $l_{f}$, top diameter $d_{f t}$ and bottom diameter $d_{f b}$, they are optimized using the numerical simulation next. As shown in Table 8 , when $l_{f}=660 \mathrm{~mm}, d_{f b}=120 \mathrm{~mm}$, $d_{f t}=100 \mathrm{~mm}$, the uniformity of pressure drop can reach the maximum of $96.6274 \%$, which is higher than the uniformity of tube and cone. Effects of three parameters $d_{f t}, d_{f b}$ and $l_{f}$ on the pressure drop are shown in Fig. 9. The distribution of pressure drop at the height $l_{f}$ of $650 \mathrm{~mm}, 660 \mathrm{~mm}$ and $670 \mathrm{~mm}$ is shown in Fig. 13(a), Fig. 13(b) and Fig. 13(c), respectively. 


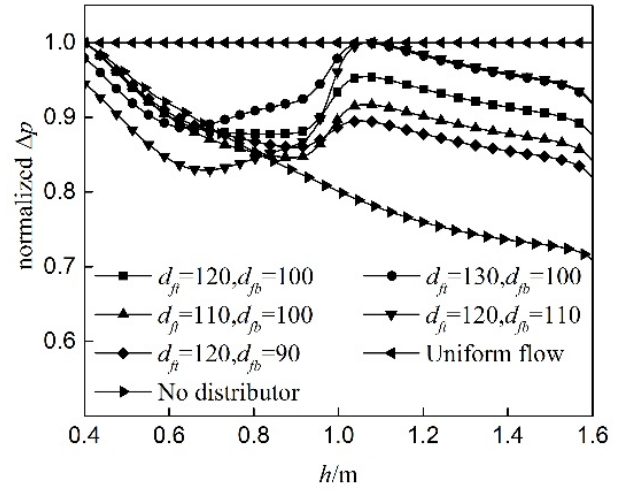

(a) $l_{f}=650 \mathrm{~mm}$

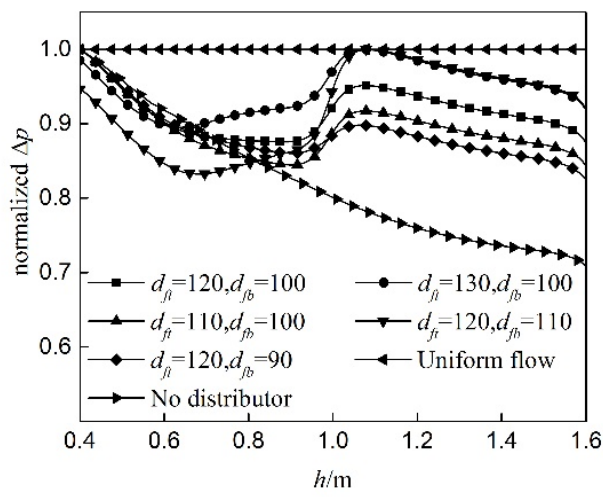

(b) $l_{f}=660 \mathrm{~mm}$

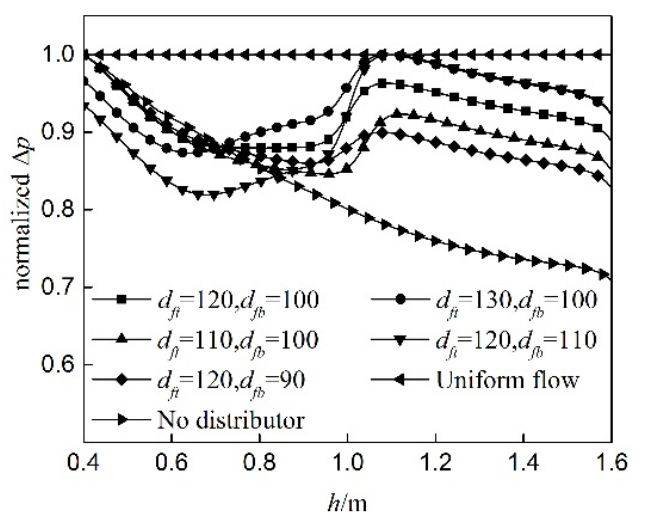

(c) $l_{f}=670 \mathrm{~mm}$

Figure 13: Changes of normalized pressure drop along with the height and diameter of truncated cone during desorption process.

\subsection{Comparison of velocity contours in desorption process}

Since the axial velocity is very small in adsorption area, the airflow distribution can be characterized by radial velocity. Contours of radial velocity in the desorption process under different structures of distributor are shown in Fig. 14. Among them, contours of the radial velocity in original model are displayed in Fig. 14(a), and the desorption pressure drop uniformity is $90.07 \%$. The optimized distributor with truncate cone of $660 \mathrm{~mm}$ in height, $120 \mathrm{~mm}$ in bottom diameter and $100 \mathrm{~mm}$ in top diameter are revealed in Fig. 14(b). From Table 8, it can be concluded that the uniformity of desorption pressure drop under these structural parameters is $96.6274 \%$. It is can also be demonstrated by the comparison of two contours that uniformity of the radial velocity in the optimized model is higher 


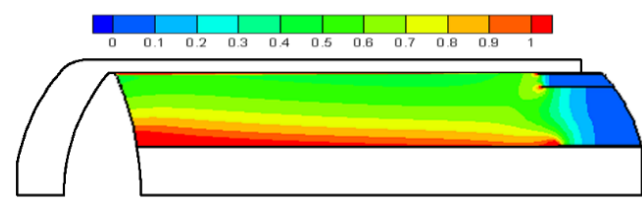

(a) Velocity contours of original model

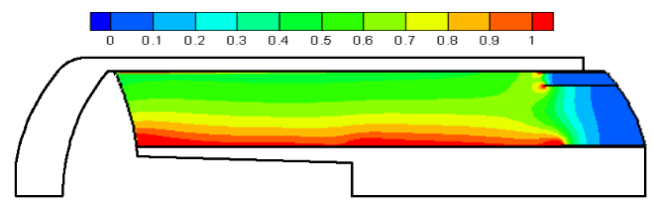

(b) Velocity contours of optimized model

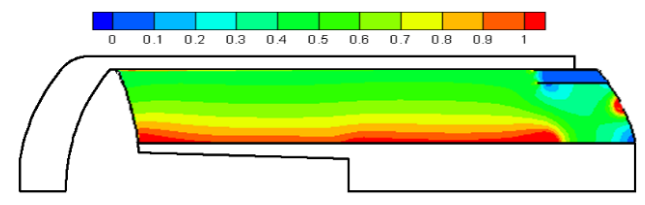

(c) Velocity contours of model with breathing value

Figure 14: Contours of radial velocity under different designs during desorption process.

than that in the original model. Even so, some limitations still exist in the optimized adsorber. Due to the requirement of weight-bearing, the top of adsorber is generally set as imperforated plates, which results in the fact that flow velocity in the top of adsorber approaches zero, it is often called "dead zone". In this area, insufficient desorption will lead to excessive carbon dioxide. In response to this problem, a method of installing a breathing valve at the top of adsorber is presented in this paper, as shown in Fig. 14(c). The breathing valve is opened during desorption and the air flow is partially discharged from the breather valve to avoid the "dead zone". It can be seen from Fig. 14(c), the change of flow uniformity in the adsorber is only $0.004554 \%$, which can be neglected, but the problem of "dead zone" at the top of adsorber is effectively solved, which ensures a long-term and effective work of adsorber.

\subsection{Analysis of adsorption effect}

The adsorption process is also very important since it determines the adsorption efficiency of the adsorber. From Fig. 10(a) and Fig. 10(b), it can be seen that the pressure drop of adsorption and desorption processes has a similar downward trend from $0.4 \mathrm{~m}$ to $1.0 \mathrm{~m}$. Actually, the optimal design of distributor in desorption process also plays a positive role in the adsorption process. Generally, $\mathrm{CO}_{2}$ is considered to reach a breakthrough if its concentration is in excess of $1 \mathrm{ppm}$ at outlet, then it switches into the desorption process. So, the concentration profile of $\mathrm{CO}_{2}$ at the outlet was monitored, the relation curves that concentration varies with time, that is, the breakthrough curve are obtained. The adsorber is mainly used to adsorb $\mathrm{CO}_{2}$ in the air, the longer the $\mathrm{CO}_{2}$ penetrates the adsorbent, the better the performance of adsorber under the same amount of feed air. The comparison of breakthrough curves between the original and optimized model is shown in Fig. 15 It is indicated that breakthrough time of the optimized model is obviously pro- 


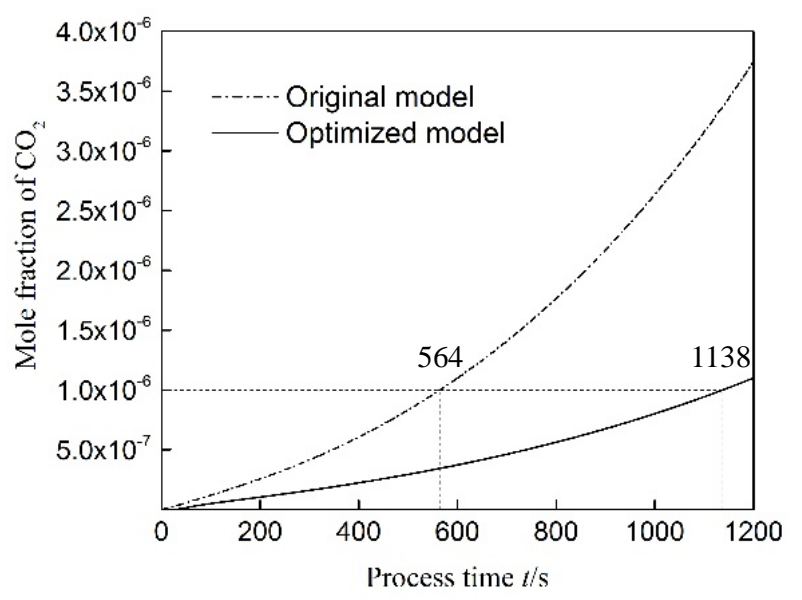

Figure 15: Changes of mole fraction of $\mathrm{CO}_{2}$ along with process time during the adsorption process.

longed from 564s to 1138s, the longer the $\mathrm{CO}_{2}$ is monitored at outlet, means it is adsorbed more completely.

\section{Conclusions}

In this paper, numerical simulation based on the CFD software is adopted to solve the problem of uneven distribution of air flow in radial flow adsorber. Based on desorption process, the structure of the distributor in the center channel of adsorber is compared and then the optimal design is obtained. Finally, the problem of "dead zone" at the top of adsorber is presented, analyzed and treated for the improvement. The specific conclusions are as follows:

(1) Numerical simulation based on the computational fluid dynamics software ANSYS Fluent 15.0 is adopted to simulate the flow distribution in radial flow adsorber. The numerical methods were validated against the published results, and the CFD simulation results were in good agreement with the experimental data.

(2) The pressure drop distribution is non-uniform in both adsorption and desorption processes. Through the calculations of pressure drop uniformity, the uniformity of adsorption and desorption process is $97.13 \%$ and $90.07 \%$, respectively, which indicates the air flow in desorption process is more uneven compared to that in adsorption process.

(3) It is found that the truncated cone is more efficient than tube and cone in the flow distribution. The structure of truncated cone can simultaneously improve the uniformity of adsorption and desorption. By inserting the truncated cone in central 
channel, desorption uniformity is increased by $6.56 \%$ and the breakthrough time of adsorption process can extend from $564 \mathrm{~s}$ to $1138 \mathrm{~s}$.

(4) The problem of "dead zone" at the top of adsorber during the desorption process can be effectively solved by opening breathing valve, which prolongs the service life of adsorber.

\section{Nomenclature}

$\begin{array}{ll}C & \text { DA equation parameter } \\ C_{2} & \text { inertial resistance factor } \\ D_{k} & \text { Knudsen diffusion coefficient } \\ D_{L} & \text { axial dispersion coefficient } \\ D_{m} & \text { molecular diffusion coefficient } \\ D_{p} & \text { pore diffusivity } \\ d_{p} & \text { diameter of adsorbent particles, } \mathrm{m} \\ d_{x} & \text { plate thickness, } \mathrm{m} \\ E & \text { total energy, } \mathrm{J} \cdot \mathrm{kg}^{-1} \\ F & \text { energy distribution function of adsorbent surface, } \mathrm{mol} \cdot \mathrm{kJ}^{-1} \\ g & \text { acceleration of gravity, } \mathrm{m} \cdot \mathrm{s}^{-2} \\ H & \text { dimensionless height } \\ \Delta H & \text { adsorption heat, } \mathrm{J} \cdot \mathrm{mol}{ }^{-1} \\ h & \text { height of adsorber, } \mathrm{m} \\ k & \text { mass transfer coefficient } \\ k_{c} & \text { LDF mass transfer coefficient, } \mathrm{s}^{-1} \\ k_{c}^{0} & \text { uncorrected LDF mass transfer coefficient, } \mathrm{s}^{-1} \\ k_{\mathrm{f}} & \text { film mass transfer coefficient, } \mathrm{s}^{-1} \\ k_{e f f} & \text { effective heat transfer coefficient, } \mathrm{w} \cdot \mathrm{m}^{-2} \cdot \mathrm{k}^{-1} \\ M & \text { molar mass, } \mathrm{kg} \cdot \mathrm{mol}^{-1} \\ m & \text { DA equation parameter } \\ n & \text { number of data } \\ P & \text { partial pressure, Pa } \\ P_{s} & \text { saturation pressure, Pa } \\ \end{array}$




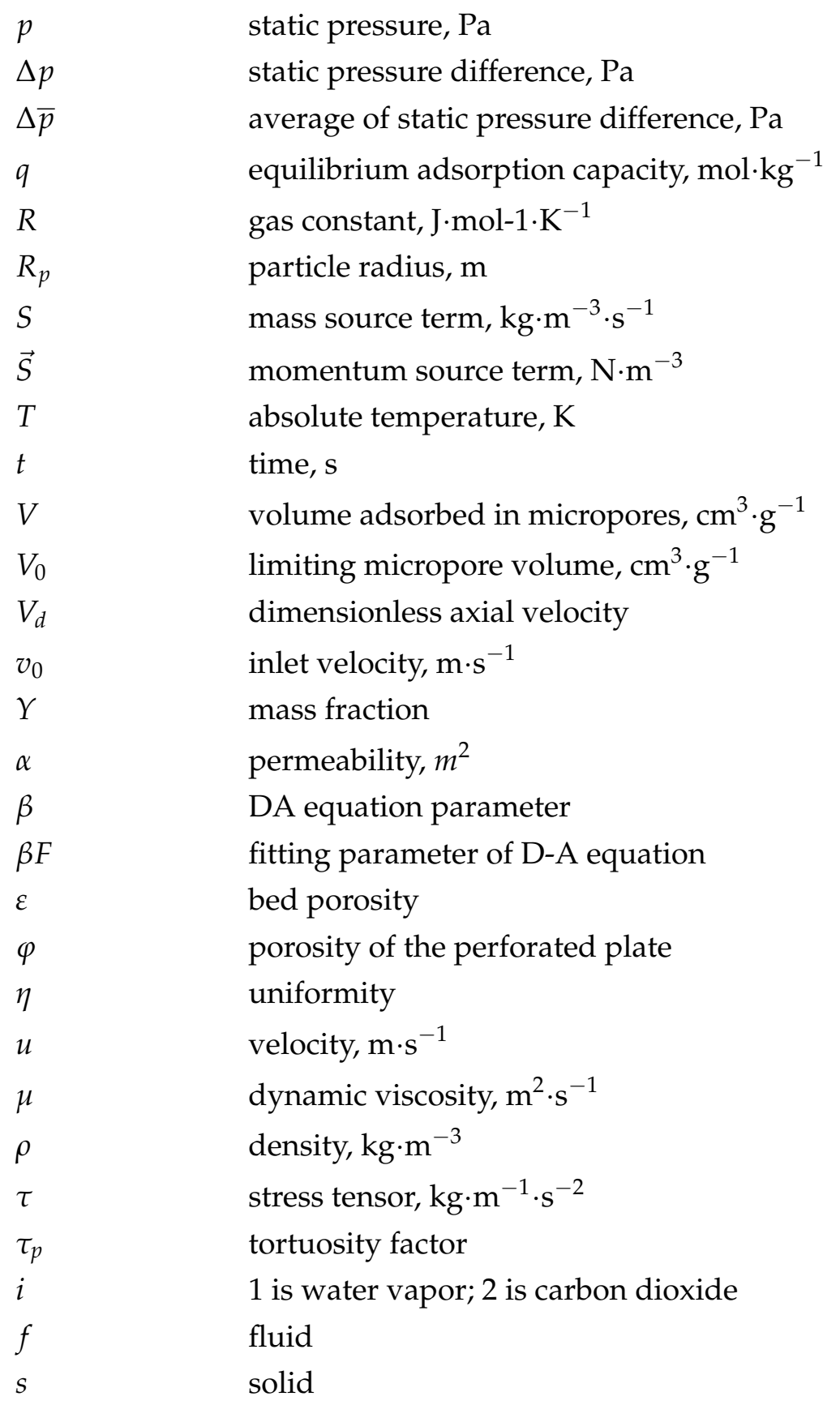

\section{Acknowledgements}

The project is funded by the Fundamental Research Funds for the Central Universities with No. 3082017NS2017005. 


\section{References}

[1] K. D. Timmerhaus And R. P. Reed, Cryogenic engineering: Fifty Years of Progress, New York: Springer, 2007.

[2] W. F. CASTLE, Air separation and liquefaction: recent developments and prospects for the beginning of the new millennium, Int. J. Refrigeration, 25(1) (2002), pp. 158-172.

[3] G. K. FRANK, Industrial Gas Handbook, Florida: CRC Press, 2006.

[4] S. U. Rege, R. T. YANG AND K. QIAN ET AL., Air prepurication by pressure swing adsorption using single/layered beds, Chem. Eng. Sci., 56 (2001), pp. 2745-2759.

[5] J. LU, X. ZHANG AND L. QIU ET AL., Theoretical analysis of uniform flow distribution in vertical radial adsorption bed, J. Chem. Industry Eng., s2 (2012), pp. 21-25.

[6] X. J. ZHANG, J. L. LU AND L. M. QIU ET AL., A mathematical model for designing optimal shape for the cone used in Z-flow type radial flow adsorbers, Chinese Journal of Chemical Engineering, 21(5) (2013), pp. 494-499.

[7] H. Y. WANG, Y. H. LIU AND X. YANG, Progress in air pre-purification technology, Chem. Industry Eng. Progress, 33(3) (2014), pp. 542-549.

[8] H. Y. WANG, Y. H. LIU AND Y. MENG, Effect of the gas distribution system structure of a radial flow adsorber on gas distribution, Chinese J. Eng., 2015, 37(1) (2015), pp. 91-96.

[9] F. MebareK-OUdinA AND O. D. MAKINDE, Numerical simulation of oscillatory MHD natural convection in cylindrical annulus: Prandtl Number Effect, Defect and Diffusion Forum, 387 (2018), pp. 417-427.

[10] F. MEBAREK-OUdiNA AND H. R. BESSAÏ, Numerical modeling of MHD stability in a cylindrical configuration, J. Franklin Institute, 351(2) (2014), pp. 667-681.

[11] F. MebareK-Oudina, Numerical modeling of the hydrodynamic stability in vertical annulus with heat source of different lengths, Eng. Sci. Tech., 20(4) (2017), pp. 1324-1333.

[12] A. KAREERI, H. ZUGHBI AND H. AL-Al, Simulation of flow distribution in radial flow reactors, Industrial Eng. Chem. Res., 45 (2006), pp. 2862-2874.

[13] V. GENKIN, V. Dil-MAN AND S. SERGEEV, The distribution of a gas stream over a radial contact apparatus, Industrial Chem. Eng., (1973), pp. 13-24.

[14] Z. L. TANG, M. Y. XU AND J. ZHANG, Simulation and analysis on gas flow distribution in radial flow air adsorber, Journal of Tianjin University, 49(3) (2016), pp. 305-312.

[15] D. Z. RUI, X. J. ZHANG AND Y. CHEN ET AL., Simulation of flow field in vertical radial flow adsorber with parallel connection device, Chinese J. Chem. Eng., 66(11) (2015), pp. 4485-4492.

[16] Q. Q. TIAN, G. G. HE AND Z. P. WANG ET AL., A novel radial adsorber with parallel layered beds for prepurification of large-scale air separation units, Industrial Eng. Chem. Res., 54(30) (2015), pp. 7502-7515.

[17] Y. LI, H. Q. SI AND B. WANG ET AL., Optimization design research of air flow distribution in vertical radial flow adsorbers, Korean J. Chem. Eng., 35(4) (2018), pp. 835-846.

[18] W. C. HUANG AND C. CHOU, Comparison of radial-and axial-flow rapid pressure swing adsorption processes, Industrial Eng. Chem. Res., 42(9) (2003), pp. 1998-2006.

[19] Y. CHEN, X. J. ZHANG AND J. LU ET AL., Flow characteristics of radial flow adsorber and its structure parameters optimization, Chinese J. Chem. Eng., 65(9) (2014), pp. 3395-3402.

[20] Z. S. DAI, M. YU AND D. Z. RUI ET AL., Investigation on a vertical radial flow adsorber designed by a novel parallel connection method, Chin. J. Chem. Eng., 26(3) (2018), pp. 484-493.

[21] P. J. HegGs, D. I. Ellis AND M. S. IsmaIL, Prediction of flow distributions and pressure changes in multi-layered annular packed beds, Gas Separation \& Purification, 9(4) (1995), pp. 243-252.

[22] M. PetKovsKa, D. ANTOV AND P. Sullivan, Electrothermal desorption in an annular- 
radial flow-ACFC adsorber-mathematical modeling, Adsorption J. Int. Adsorption Society, 11(1) (2005), pp. 585-590.

[23] D. H. KO, I. MoON AND D. CHOI, Analysis of the contact time in a cyclic thermal swing adsorption process, Ind. Eng. Chem. Res., 41(6) (2002), pp. 1603-1615.

[24] K. N. Son, J. A. Weibel AND J. C. KNOX ET AL., Calibration and uncertainty analysis of a fixed-bed adsorption model for $\mathrm{CO}_{2}$ separation, Adsorption, 24 (2018), pp. 781-802.

[25] T. K. SHerwOOd, C. R. Wilke AND R. L. Pigford, Mass Transfer, McGraw-Hill, 1975.

[26] A. KAPOOR AND R. T. YANG, Kinetic separation of methane-carbon dioxide mixture by adsorption on molecular sieve carbon, Chem. Eng. Sci., 44(8) (1989), pp. 1723-1733.

[27] F. EPIEPANG, J. Li AND Y. LIU ET AL., Low-pressure performance evaluation of $\mathrm{CO}_{2}, \mathrm{H}_{2} \mathrm{O}$ and $\mathrm{CH}_{4}$, on Li-LSK as a superior adsorbent for air prepurification, Chem. Eng. Sci., 147 (2016), pp. 100-108.

[28] S. PATANKAR, Numerical Heat Transfer and Fluid Flow, CRC Press, 1980.

[29] X. SONG, A. Z. WANG AND Y. JIN ET AL., Investigations on hydrodynamics of radial flow moving bed reactors, Chem. Eng. Tech., 16(6) (1993), pp. 383-388.

[30] G. Li, P. XIAO AND P. A. Webley eT AL., Competition of $\mathrm{CO}_{2} / \mathrm{H}_{2} \mathrm{O}$ in adsorption based $\mathrm{CO}_{2}$ capture, Energy Procedia, 1(1) (2009), pp. 1123-1130.

[31] G. Li, P. XIAO AND P. A. Webley ET AL., Capture of $\mathrm{CO}_{2}$ from high humidity flue gas by vacuum swing adsorption with zeolite 13X, Adsorption, 14(2-3) (2008), pp. 415-422.

[32] G. LI, P. XIAO AND J. ZHANG ET AL., The role of water on post-combustion $\mathrm{CO}_{2}$ capture by vacuum swing adsorption: Bed layering and purge to feed ratio, AIChE J., 60(2) (2014), pp. 673689. 